\title{
Study and Assessment of Low Frequency Noise in Occupational Settings
}

\author{
Adel M. SHEHAP ${ }^{(1)}$, Hany A. SHAWKY ${ }^{(2)}$, Tarek M. EL-BASHEER ${ }^{(2)}$ \\ (1) Department of Physics, Faculty of Science, Cairo University \\ Giza, Egypt \\ (2) Department of Acoustic, Mass and Force Metrology Division, National Institute for Standards NIS \\ Giza, Egypt; e-mail: hanysho@yahoo.com,tarek31.uv@gmail.com
}

(received August 26, 2015; accepted November 20, 2015)

\begin{abstract}
Low frequency noise is one of the most harmful factors occurring in human working and living environment. Low frequency noise components from 20 to $250 \mathrm{~Hz}$ are often the cause of employee complaints. Noise from power stations is an actual problem for large cities, including Cairo. The noise from equipments of station could be a serious problem for station and for environmental area. The development of power stations in Cairo leads to appearing a wide range of gas turbines which are strong source of noise. Two measurement techniques using C-weighted along side the A-weighted scale are explored. C-weighting is far more sensitive to detect low frequency sound. Spectrum analysis in the low frequency range is done in order to identify a significant tonal component. Field studies were supported by a questionnaire to determine whether sociological or other factors might influence the results by using annoyance rating mean value. Subjects included in the study were 153 (mean $=36.86, \mathrm{SD}=8.49$ ) male employees at the three electrical power stations. The (C-A) level difference is an appropriate metric for indicating a potential low frequency noise problem. A-weighting characteristics seem to be able to predict quite accurately annoyance experienced from LFN at workplaces. The aim of the present study is to find simple and reliable method for assessing low frequency noise in occupational environment to prevent its effects on work performance for the workers. The proposed method has to be compared with European methods.
\end{abstract}

Keywords: low frequency noise; A-weighting; C-weighting; audible; method of assessment.

\section{Introduction}

Although the international definition of low frequency noise (LFN) is missing, it is considered as the broad band noise in the frequency range from about 10 to $250 \mathrm{~Hz}$. LFN spans part of the infrasonic and low audible frequency, many effects attributed the earlier to infrasound are also believed to be exerted by LFN (Persson, 1995; Berglund et al., 1996; Broner, 1978). Sound in the frequency range below $20 \mathrm{~Hz}$ is defined as infrasound. The infrasound can be heard (or left) provided it is loud enough. The infrasound is usually not perceived as a tonal sound but rather as a pulsating sensation, pressure on the ears or chest. LFN is ubiquitous not only in the general environment but also at workplaces, especially in industrial control rooms and offices (BERGLUND et al., 1996; LEVENTHALL et al., 2003).

Generally, LFN effects are less recognized when compared to the effects of noise at higher frequencies.
However, the importance of LFN in the general environment was pointed out in the WHO document on community noise (BERGLund et al., 2000). The specific regulations on its control in the general environment are in use in some European countries. However, no guidelines for working environment have been established so far. Only recommendations for LFN in the occupational environment have been proposed in Sweden (Persson, 2002). Several studies have shown the differences in the degree of annoyance caused by exposure to low and medium or high frequency noise at the same A-weighted sound pressure levels. The annoyance experienced from LFN seems to be higher than that from noise without dominant low frequency components. Moreover, this effect is frequently present at relatively low sound pressure levels that comply with guidelines based on ordinary environmental noise (Persson, 1995; Berglund et al., 1996). It has been shown that exposure to LFN is often accompanied by many subjective effects such as tiredness, feeling of irri- 
tation, unease or stress, headache, pulsating feeling or feeling of pressure on the eardrum, nausea or dizziness. Some of these symptoms, especially fatigue, concentration problems, headache and irritation, can reduce working capacity (PERsson, 1995).The aim of recent study is to recommend a method for assessing LFN in occupational environment, suitable for use by Occupational Safety and Health in Egypt.

\section{Methodology}

\subsection{Procedure and tools}

This survey was a field study. Several tools were used to model noise in the workplaces and estimate the operator noise exposure in participating electric power stations as described below.

\subsection{Noise measurements}

In this study, noise levels measurements were estimated from $L_{e q}$ values. dBA used in the study approaches the perception of the human ear and is the most commonly measured metric of sound.

\subsection{Sound frequency analysis}

Sound level meter model type 2260 (Brüel \&Kjaer, Denmark) of accuracy $0.7 \mathrm{~dB}$ and resolution $0.1 \mathrm{~dB}$ is used to measure low frequency noise in different places. By analysing the spectra of acoustic noise frequencies, the equipment was positioned at a height of $1.2 \mathrm{~m}$ above the ground.

\subsection{Measurement location}

We measured low frequency noise in offices, laboratories and control rooms near turbine in three electric power stations (Shopra Elkhiema, Cairo West and Cairo South). The noise should be measured at least at 3 points in each room. One point is chosen near a corner, 0.5 to $1 \mathrm{~m}$ from the adjoining walls and 1 to $1.5 \mathrm{~m}$ above the floor. The other points are chosen to represent typical habitation in the room, at least $0.5 \mathrm{~m}$ from walls and large pieces of furniture and 1 to $1.5 \mathrm{~m}$ above the floor. Often the occupants can identify points where a noise level is the highest, and it is important to perform the measurements at these points. The measurement at each point was repeated four times, the average and standard deviation taken for each point of measurement. Software of sound level meter 2260 used was adjusted so the duration of each measurement was 1 min. The working range of used microphone is the audible range and we cannot use it for measurement of infrasound below $16 \mathrm{~Hz}$. The measurements were made in typical conditions of their operation. Noise conditions in the control rooms were verified by in situ measurements and evaluated according to proposed assessment criteria. Oliva et al., (2011) developed a reliable method for the measurement of low frequency noise in all kinds of rooms such as industrial control rooms. They based the method on some national measurement standards (i.e. Sweden, Denmark, Poland and ISO 16032, 2004). 153 health male subjects aged 20 to 59 (mean $=36.86$, $\mathrm{SD}=8.49)$ participated in this study. None of the subjects reported any hearing (subjects were selected with normal HL) nor healthy problems (no history of cardiovascular diseases). The total length of employment for workers in three stations is (1-36 years \pm 8.6$)$, most of them are educated (50.6\% university, $23.2 \%$ high school and $26.2 \%$ others) and they understood clearly the objective of the study. Most of them were collaborating (cooperative) and simplified the effort done to do the study. Exposure to LFN was preceded by a questionnaire survey: (1) basic information concerning age, education, workplace, length of employment; (2) sources of noise and its character in each location of measurement; (3) subjective feelings and complaints associated with exposure to noise at workplace and assessment of its annoyance on a 100-score scale.

\subsection{Statistical analysis}

All the obtained measurements were compared by repeated measures by using one way ANOVA and calculate standard deviation (SD). A number of criteria has been developed for assessment of low frequency noise (Broner, LEVEnthall, 1983). In recent years, some European countries have adopted national criteria for low frequency noise, including Sweden, Denmark, Germany, Netherland and Poland. Generally, all of them are based on frequency analysis in $1 / 3$ octave bands in various frequency range from $8 \mathrm{~Hz}$ to $250 \mathrm{~Hz}$. In majority cases, measured sound pressure levels are compared with criterion curves as shown in Table 1. Outline Swedish recommendations for assessing LFN at workplaces are based on $1 / 3$ octave band measurements in the frequency range 25 to $200 \mathrm{~Hz}$ (PERSSON, 2002).

Relationships between age, length of work, exposure to noise at the workplace, and the annoyance assessment of reproduced signals were analysed using Pearson's correlation coefficient $(r)$. A value of $p<0.05$ was considered to indicate statistical significance. SPSS 16.00 software was used to find the correlation.

The proposed criteria for assessing work environmental exposure to LFN are based on literature data concerning LFN effects on humans, the existing evaluation methods and the results of LFN measurements at workplaces. First of all, an assumption was made that the difference between $\mathrm{C}$ - and A-weighted sound pressure levels $\left(L_{C}-L_{A}\right)$ exceeding $15 \mathrm{~dB}$ indicates the occurrence of LFN (PERSSON WAYE, 1995). 
Table 1. Reference curve used in various national criteria concerning environmental exposure to LFN according to ISO 226:2003 and an outline Swedish recommendations for workplaces (PERSSON, 2002; ISO 226, 2003; DIN 45680, 1997).

\begin{tabular}{|c|c|c|c|c|c|}
\hline \multicolumn{7}{|c|}{ Reference curve } \\
\hline $\begin{array}{c}1 / 3 \text { Octave } \\
\text { bands }[\mathrm{Hz}]\end{array}$ & German & Swedish & Dutch & Polish & British \\
\hline \multicolumn{7}{|c|}{ Sound pressure level [dB] } \\
\hline 8 & 103 & & & & \\
\hline 10 & 95 & & & 80.4 & 92 \\
\hline 12.5 & 87 & & & 73.4 & 87 \\
\hline 16 & 79 & & & 66.7 & 83 \\
\hline 20 & 71 & & 74 & 60.5 & 74 \\
\hline 25 & 63 & & 64 & 54.7 & 64 \\
\hline 31.5 & 55.5 & 56 & 55 & 49.3 & 56 \\
\hline 40 & 48 & 49 & 46 & 44.6 & 49 \\
\hline 50 & 40.5 & 43 & 39 & 40.2 & 43 \\
\hline 63 & 33.5 & 41.5 & 33 & 36.2 & 41.5 \\
\hline 80 & 28 & 40 & 27 & 32.5 & 40 \\
\hline 100 & 23.5 & 38 & 22 & 29.1 & 38 \\
\hline 125 & & 36 & & 26.1 & 36 \\
\hline 160 & & 34 & & 23.4 & 34 \\
\hline 200 & & 32 & & 20.9 & \\
\hline 250 & & & & 18.6 & \\
\hline
\end{tabular}

Three different measuring methods were proposed by (PAWLACZYK-ŁUSZCZYŃSKa et al., 2006):

a) method I - a frequency analysis in 1/3-octave bands from 10 to $250 \mathrm{~Hz}$,

b) method II - the determination of equivalentcontinuous A-weighted sound pressure level (SPL) in the frequency range $10-250 \mathrm{~Hz}$ and introduction of the penalty for tonal character of noise using the following formula:

$$
\begin{aligned}
L_{A 10-250 \mathrm{~Hz}}= & 10 \log \sum_{f} 10^{0.1\left(L_{f}+k_{f A}\right)} \\
& +K_{1}[\mathrm{~dB}]
\end{aligned}
$$

where $L_{f}$ is the SPL in the $1 / 3$ octave bands from 10 to $250 \mathrm{~Hz}, k_{f A}$ is the relative response of the A-weighting frequency characteristics for the $f$-th $1 / 3$ octave band in $\mathrm{dB} ; K_{1}$ is the penalty for tonal character of noise.

c) method III - based on an equivalent continuous A-weighted SPL corrected due to presence of low frequencies $\left(K_{2}\right)$ and tonal character of noise $\left(K_{1}\right)$, expressed in Eq. (2):

$$
L_{A, \mathrm{LFN}}=L_{A e q, T e}+K_{1}+K_{2}[\mathrm{~dB}],
$$

where $L_{A e q, T e}$ is the equivalent continuous A-weighted SPL in $\mathrm{dB}, K_{1}$ is the penalty for tonal character of noise and $K_{2}$ is the penalty for presence of low frequency component in the spectrum.

This study depends on method I for measurement a frequency analysis in $1 / 3$-octave bands from 16 to $250 \mathrm{~Hz}$ (audible range). An assumption was made that the difference between $\mathrm{C}$ - and A-weighted sound pressure levels $\left(L_{C}-L_{A}\right)$ exceeding $15 \mathrm{~dB}$ indicates the occurrence of LFN.

\subsection{Audibility assessment}

The following tests are made:

1) determining $L_{\text {Aeq }}$ levels inside each affected room,

2) determining if $L_{C}-L_{A}>15 \mathrm{~dB}$,

3) comparing these levels with the hearing threshold given in Table 2 to determine the degree of low frequency noise audibility.

Table 2. Median hearing threshold levels (ISO 1996-1, 2003).

\begin{tabular}{|c|c|}
\hline $\begin{array}{c}1 / 3 \text { Octave band } \\
\text { frequency } \\
{[\mathrm{Hz}]}\end{array}$ & $\begin{array}{c}\text { Hearing threshold } \\
{[\mathrm{dB}]}\end{array}$ \\
\hline 8 & 96 \\
\hline 10 & 92 \\
\hline 12.5 & 88 \\
\hline 16 & 84 \\
\hline 20 & 75 \\
\hline 25 & 62 \\
\hline 31.5 & 55 \\
\hline 40 & 46 \\
\hline 50 & 39 \\
\hline 63 & 33 \\
\hline 80 & 27 \\
\hline 100 & 22 \\
\hline 125 & 18 \\
\hline 160 & 14 \\
\hline 200 & 10 \\
\hline & \\
\hline
\end{tabular}

\section{Results}

\subsection{Measurement of noise and spectrum analysis}

Noise analysis was performed at three locations: offices, laboratories and control rooms near turbine in three electric power stations (Shopra Elkhiema, Cairo West and Cairo South).

Since the objective of this study is to find simple and reliable method for assessing low frequency 
noise in occupational environment to prevent its effects on work performance and concentration for the workers. Thus, three different evaluation methods were proposed. Two of them, method I and method II, are based on frequency analysis in $1 / 3$-octave bands. However, the latter one, like in the Danish assessment method for LFN in dwellings, nominal A-weighting corrections are added to spectra, and the weighted spectrum is summed up to form the low frequency A-weighted SPL. Method III is simply based on the equivalent-continuous A-weighted sound pressure level, but penalties due to the presence of low frequency components in the spectrum and tonal character of noise are added. For method I, various criterion curves were proposed in order to find out the best one. Most of them were modeled after existing reference curves for assessing LFN in the general environment. Since the field study is more realistic than laboratory study we were not in need for verification by laboratory study. Our study was based on method I based on $1 / 3$ octave band frequency analysis and determination of some noise parameters.

Noise parameters were determined, e.g. $L_{A e q, T}$, $L_{C e q, T}, L_{C}-L_{A}$ and noise climate $L_{10}-L_{90}$, for each measurement location. The measurements started in Shopra Elkhiema electrical power station. Figure 1 shows the noise spectra measured at control rooms, laboratories and offices within frequency range of 16$250 \mathrm{~Hz}$. The low frequency noises that cause complaints in control rooms, laboratories and offices are usually generated by the air conditioning or ventilation system, turbines, transformers and water pumps which are present in the station. Table 3 shows the measurement parameters selected for the study of low frequency noise in station. The acoustic pressure at $50 \mathrm{~Hz}$ is due to air conditioning which is audible especially in the control room because it exceeds $50 \mathrm{~dB}$. Also, in some offices the sound of air condition causes annoyance and makes workers complain. Both control rooms and laboratory are located near turbine. Also, the building which contains offices located near water pumps. The second measurements were carried out in Cairo West electrical power station. Figure 2 shows the noise spectra measured at control rooms, laboratories and offices within frequency range of 16-250 Hz. Also, Table 4 shows the measurement parameters selected for the study of low frequency noise in this station.

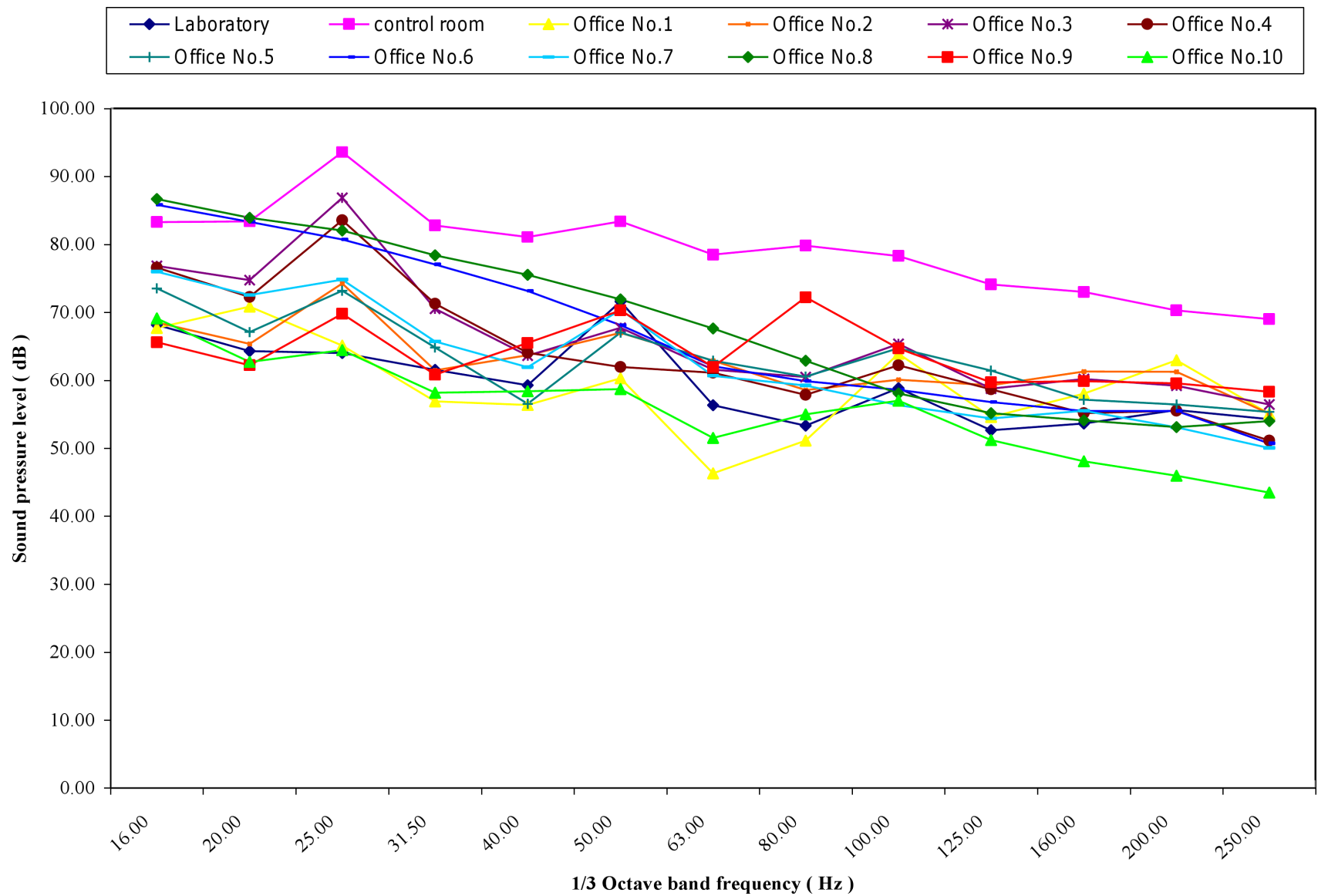

Fig. 1. The noise spectra measured at laboratory, control room and 10 offices in Shopra Elkhiema electrical power station. 
Table 3. Parameters of low frequency noise LFN in laboratories, control rooms and offices of Shopra Elkhiema electrical power station (SD - standard deviation).

\begin{tabular}{|c|c|c|c|c|c|c|}
\hline \multicolumn{7}{|c|}{ Shopra Elkhiema electrical power station } \\
\hline \multirow{2}{*}{ Location } & \multicolumn{2}{|c|}{$\begin{array}{c}\text { Equivalent continuous SPL }[\mathrm{dB}] \\
\text { Mean }(\mathrm{SD})\end{array}$} & \multirow{2}{*}{$L_{C}-L_{A}$} & \multirow{2}{*}{$L_{10}$} & \multirow{2}{*}{$L_{90}$} & \multirow{2}{*}{$L_{10}-L_{90}$} \\
\hline & $\begin{array}{c}\text { A-weighted } \\
L_{A e q, T}\end{array}$ & $\begin{array}{c}\text { C-weighted } \\
L_{C e q, T}\end{array}$ & & & & \\
\hline Laboratory & $51.3(0.34)$ & $77.5(0.73)$ & $26.2(0.40)$ & $71.6(0.67)$ & $68.4(0.59)$ & $3.2(0.16)$ \\
\hline Control room & $65.9(0.43)$ & $81.5(0.56)$ & $15.6(0.37)$ & $81.8(0.16)$ & $79.3(0.38)$ & $2.5(0.25)$ \\
\hline Office No. 1 & $55.5(0.28)$ & $70.8(0.35)$ & $15.3(0.07)$ & $70.8(0.28)$ & $68.4(0.14)$ & $2.4(0.14)$ \\
\hline Office No. 2 & $56.6(0.21)$ & $72.6(0.14)$ & $16.0(0.07)$ & $72.4(0.14)$ & $70.4(0.14)$ & $2.0(0.07)$ \\
\hline Office No. 3 & $56.9(0.07)$ & $73.2(0.07)$ & $16.3(0.14)$ & $74.2(0.07)$ & $71.8(0.14)$ & $2.4(0.14)$ \\
\hline Office No. 4 & $53.0(0.14)$ & $72.8(0.21)$ & $19.8(0.07)$ & $74.4(0.14)$ & $70.4(0.28)$ & $4.0(0.14)$ \\
\hline Office No. 5 & $55.9(0.21)$ & $73.0(0.28)$ & $17.1(0.49)$ & $74.0(0.84)$ & $71.6(0.07)$ & $2.0(0.84)$ \\
\hline Office No. 6 & $55.6(0.07)$ & $74.4(0.14)$ & $18.7(0.14)$ & $76.4(0.14)$ & $71.4(0.07)$ & $5.0(0.14)$ \\
\hline Office No. 7 & $52.5(0.13)$ & $68.2(0.48)$ & $15.7(0.14)$ & $70.4(0.12)$ & $65.2(0.42)$ & $5.2(0.16)$ \\
\hline Office No. 8 & $55.6(0.35)$ & $77.2(0.42)$ & $21.6(0.49)$ & $80.4(0.56)$ & $77.8(0.14)$ & $2.6(0.84)$ \\
\hline Office No. 9 & $62.5(0.55)$ & $78.1(0.34)$ & $15.6(0.20)$ & $78.6(0.78)$ & $77.6(0.35)$ & $1.0(0.14)$ \\
\hline Office No. 10 & $48.9(0.42)$ & $66.1(0.91)$ & $17.2(0.42)$ & $66.8(0.14)$ & $64.4(0.14)$ & $2.4(0.28)$ \\
\hline
\end{tabular}

\begin{tabular}{|c|c|c|c|c|}
\hline $\begin{array}{l}\longrightarrow \text { Laboratory No.1 } \\
\longrightarrow \text { office No.2 }\end{array}$ & $\begin{array}{l}\rightarrow \text { - Laboratory No.2 } \\
\text {, Office No.3 }\end{array}$ & $\begin{array}{l}- \text { Control room No.2 } \\
- \text { Office No.4 }\end{array}$ & $\begin{array}{l}\rightarrow \text { - Control room No.1 } \\
=\text { Office No.5 }\end{array}$ & $\begin{array}{l}* \text { Office No.1 } \\
\multimap \text { Office No.6 }\end{array}$ \\
\hline
\end{tabular}

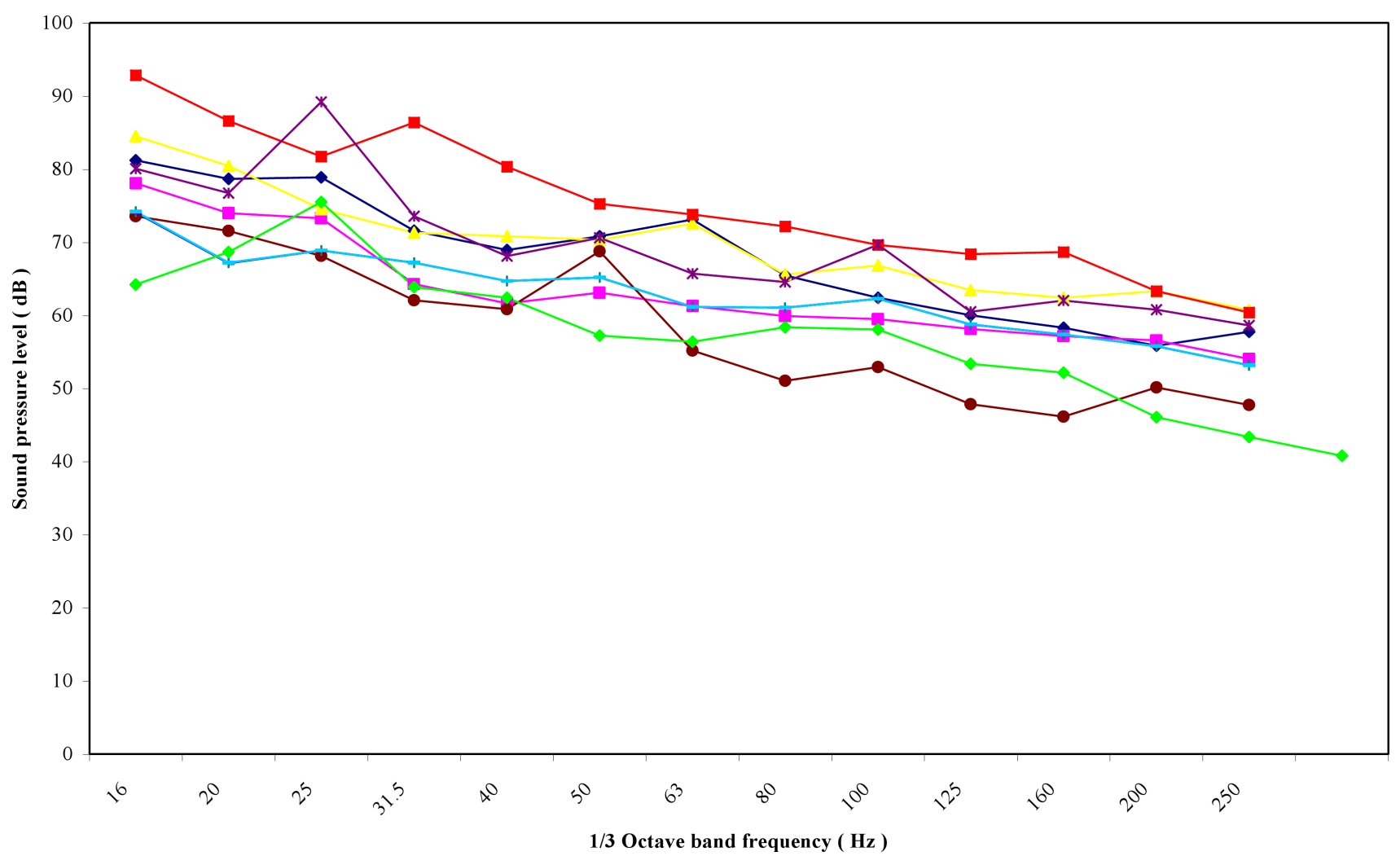

Fig. 2. The noise spectra measured at 2 laboratories, 2 control rooms and 6 offices in Cairo West electrical power station. 
Table 4. Parameters of low frequency noise LFN in laboratories, control rooms and offices of Cairo West electrical power station ( $\mathrm{SD}$ - standard deviation).

\begin{tabular}{|c|c|c|c|c|c|c|}
\hline \multicolumn{7}{|c|}{ Cairo West electrical power station } \\
\hline \multirow{2}{*}{ Location } & \multicolumn{2}{|c|}{$\begin{array}{c}\text { Equivalent continuous SPL }[\mathrm{dB}] \\
\text { Mean }(\mathrm{SD}) \\
\end{array}$} & \multirow{2}{*}{$L_{C}-L_{A}$} & \multirow{2}{*}{$L_{10}$} & \multirow{2}{*}{$L_{90}$} & \multirow{2}{*}{$L_{10}-L_{90}$} \\
\hline & $\begin{array}{c}\text { A-weighted } \\
L_{A e q, T}\end{array}$ & $\begin{array}{c}\text { C-weighted } \\
L_{C e q, T}\end{array}$ & & & & \\
\hline Laboratory No. 1 & $46.9(0.28)$ & $62.1(0.21)$ & $15.2(0.07)$ & $63.4(0.28)$ & $60.2(0.56)$ & $3.2(0.28)$ \\
\hline Laboratory No. 2 & $56.3(0.07)$ & $73.1(0.33)$ & $16.8(0.31)$ & $74.4(0.33)$ & $71.2(0.31)$ & $3.2(0.07)$ \\
\hline Control room No. 1 & $55.4(0.98)$ & $72.5(0.29)$ & $17.1(0.38)$ & $72.3(0.17)$ & $68.9(0.17)$ & $3.4(0.07)$ \\
\hline Control room No. 2 & $55.1(0.11)$ & $69.3(0.35)$ & $14.2(0.30)$ & $70.6(0.57)$ & $67.4(0.17)$ & $3.2(0.42)$ \\
\hline Office No. 1 & $48.0(0.63)$ & $62.6(0.74)$ & $14.6(0.11)$ & $62.8(0.08)$ & $61.2(0.73)$ & $1.6(0.33)$ \\
\hline Office No. 2 & $49.0(0.55)$ & $67.7(0.24)$ & $18.7(0.19)$ & $68.2(0.26)$ & $63.8(0.22)$ & $4.4(0.09)$ \\
\hline Office No. 3 & $41.1(0.65)$ & $57.5(0.35)$ & $16.4(0.23)$ & $58.3(0.11)$ & $56.0(0.07)$ & $2.3(0.15)$ \\
\hline Office No. 4 & $52.8(0.67)$ & $69.8(0.99)$ & $17.0(0.31)$ & $70.4(0.10)$ & $68.0(0.15)$ & $2.4(0.07)$ \\
\hline Office No. 5 & $50.1(0.49)$ & $64.6(0.26)$ & $14.5(0.21)$ & $64.8(0.35)$ & $59.4(0.46)$ & $5.4(0.22)$ \\
\hline Office No. 6 & $42.8(0.17)$ & $58.1(0.51)$ & $15.2(0.33)$ & $58.4(0.40)$ & $55.8(0.25)$ & $2.6(0.13)$ \\
\hline
\end{tabular}

The station has two laboratories and two control rooms because there were two units for generating electricity: old one and new one. The sound of turbine is clearly audible in the building with offices. The third field measurements were carried out in Cairo South electrical power station. Figure 3 shows the noise spectra measured at control rooms, laboratories and offices within frequency range of $16-250 \mathrm{~Hz}$. Also, Table 5 presents the measurements.

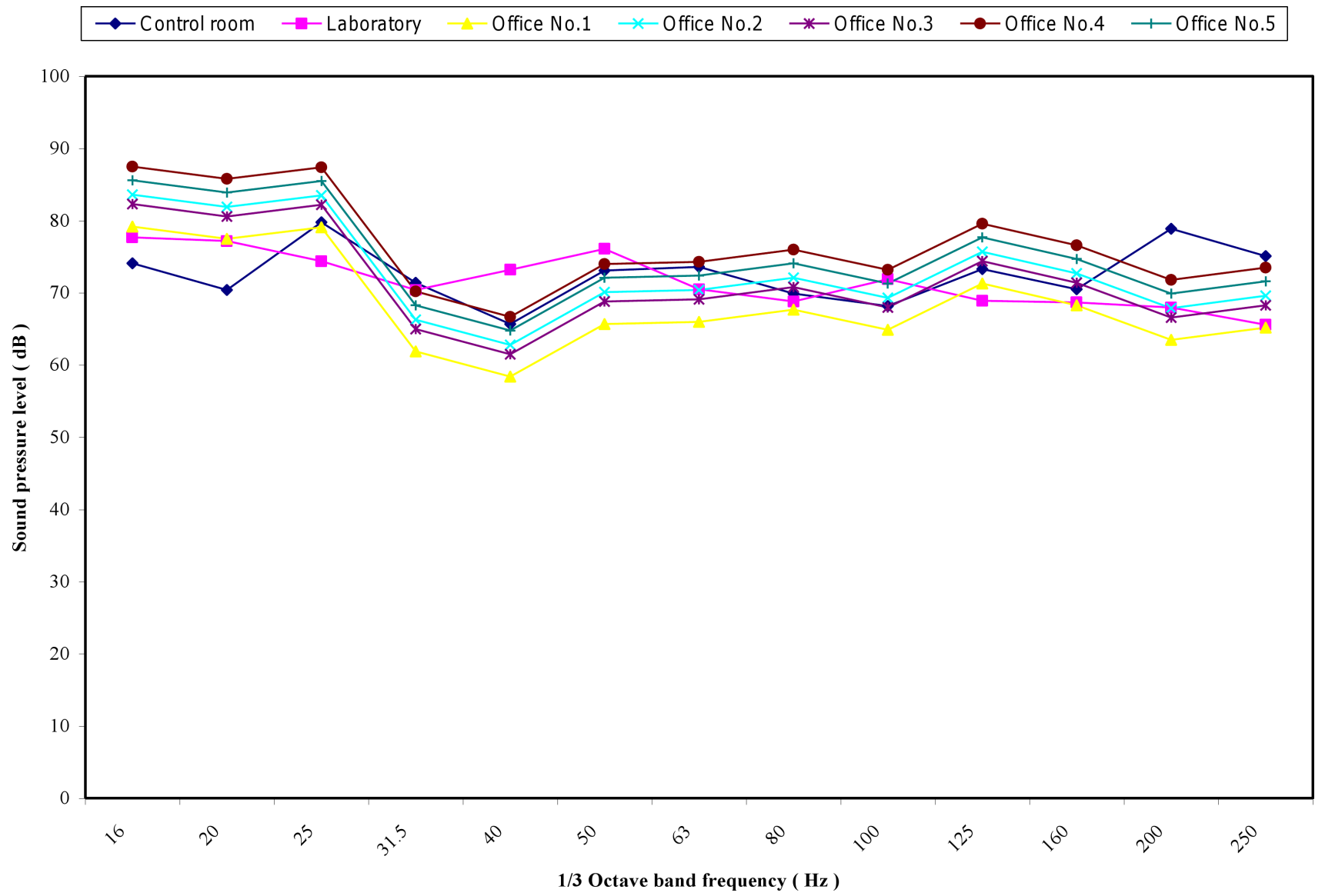

Fig. 3. The noise spectra measured at laboratory, control rooms and 5 offices in Cairo South electrical power station. 
Table 5. Parameters of low frequency noise LFN in laboratories, control rooms and offices of Cairo South electrical power station ( $\mathrm{SD}$ - standard deviation).

\begin{tabular}{|c|c|c|c|c|c|c|}
\hline \multicolumn{7}{|c|}{ Cairo South electrical power station } \\
\hline \multirow{2}{*}{ Location } & \multicolumn{2}{|c|}{$\begin{array}{l}\text { Equivalent continuous SPL }[\mathrm{dB}] \\
\text { Mean (SD) }\end{array}$} & \multirow{2}{*}{$L_{C}-L_{A}$} & \multirow{2}{*}{$L_{10}$} & \multirow{2}{*}{$L_{90}$} & \multirow{2}{*}{$L_{10}-L_{90}$} \\
\hline & $\begin{array}{c}\text { A-weighted } \\
L_{A e q, T} \\
\end{array}$ & $\begin{array}{c}\text { C-weighted } \\
L_{C e q, T}\end{array}$ & & & & \\
\hline Laboratory & $64.5(0.10)$ & $82.6(0.26)$ & $18.1(0.49)$ & $82.4(0.12)$ & $80.3(0.19)$ & $2.1(0.11)$ \\
\hline Control room & $70.5(0.28)$ & $86.9(0.81)$ & $16.4(0.13)$ & $87.4(0.40)$ & $85.6(0.50)$ & $1.8(0.33)$ \\
\hline Office No. 1 & $63.0(0.07)$ & $80.2(0.35)$ & $17.2(0.68)$ & $82.2(0.25)$ & $78.2(0.19)$ & $4.0(0.07)$ \\
\hline Office No. 2 & $59.0(0.27)$ & $75.4(0.45)$ & $16.3(0.72)$ & $75.7(0.48)$ & $73.0(0.39)$ & $2.7(0.91)$ \\
\hline Office No. 3 & $63.3(0.21)$ & $77.8(0.53)$ & $14.5(0.51)$ & $87.1(0.41)$ & $76.2(0.54)$ & $2.0(0.14)$ \\
\hline Office No. 4 & $65.1(0.24)$ & $84.1(0.75)$ & $19.0(0.34)$ & $84.7(0.38)$ & $51.7(0.66)$ & $3.3(0.49)$ \\
\hline Office No. 5 & $57.6(0.18)$ & $71.6(0.39)$ & $14.0(0.48)$ & $71.9(0.21)$ & $70.1(0.34)$ & $1.8(0.15)$ \\
\hline
\end{tabular}

Table 6. Subjective evaluation of LFN in the three electrical power stations.

\begin{tabular}{|c|c|c|c|c|c|}
\hline \multicolumn{6}{|c|}{ Annoyance rating mean value (SD) } \\
\hline Location & \multicolumn{2}{|c|}{ Laboratories } & \multicolumn{2}{|c|}{ Control rooms } & Average/offices \\
\hline Shopra Elkiema & \multicolumn{2}{|c|}{$80.5(18.62)$} & \multicolumn{2}{|c|}{$85(17.84)$} & $78.87(89)$ \\
\hline Cairo West & $\begin{array}{c}80.71(19.66) \\
\text { Lab. } 1 \\
\end{array}$ & $\begin{array}{c}75.09(16.85) \\
\text { Lab. } 2 \\
\end{array}$ & $\begin{array}{c}80.28(13.36) \\
\text { Control room } 1 \\
\end{array}$ & $\begin{array}{c}87.14(20.63) \\
\text { Control room } 2 \\
\end{array}$ & $68.29(29.0)$ \\
\hline Cairo South & \multicolumn{2}{|c|}{$65.33(12.90)$} & \multicolumn{2}{|c|}{$88.7(28.25)$} & $66.66(27.49)$ \\
\hline
\end{tabular}

The noise annoyance rating was preceded by questionnaire survey to collect (1) basic information concerning age, education, workplace, years of employment; (2) sources of noise in each room (3) the subjective feelings and complaints related with exposure to noise at workplace and the assessment of its annoyance on the 100-score scale (PERSSON WAYE, 2002). In the recent study we have found that $\mathrm{LFN}$ even at relatively low A-weighted sound pressure levels could be perceived as annoying and adversely affecting performance, particularly when mentally demanding tasks are executed. A 100-point noise annoyance scale (NAS) (Broner, Leventhall, 1983) was used as shown in Table 6.

The rating of "not annoyed", "very annoyed", "some what annoyed" and "quite annoyed" were scored as zero, 100, 25 and 75, respectively. We found from the subjective annoyance assessments of LFN in the three electrical power stations that the median value of annoyance ratings ranges from 65.33 to 87.14. The range corresponding to 'quite annoyed' corresponds with more than 50 scores on the 100-score scale. These high values are due to complaints of workers in their workplace. If we compare the values of noise rating for control rooms in three electrical power station in Table 6 with level in Tables 3, 4 and 5, we can find out that not only higher level leads to more complaints but also to high value for annoyance rat- ing. Thus, as previously studied by (PERsson WAYE, 2002) even at low levels, workers have complaints of little concentration, fatigue and the annoyance rating becomes higher. It was found that at relatively low A-weighted sound pressure levels $(55 \mathrm{~dB})$ annoyance rating for subjects appears to be near 'quite annoying', which corresponds with more than 50 scores on the 100 -score scale.

In order to analyse the relationship between various noise metrics $\left(L_{A e q, T}, L_{C e q, T}\right)$ and LFN annoyance rating analyses were made using Pearson's correlation coefficient $(r)$. A value of $p<0.05$ was considered to indicate statistical significance. It was found that there is no significant relation between the annoyance assessments of noise (dBA) of control rooms, laboratories and offices at three stations and age(years), length of employment (years). If we plot the relationship between average values of annoyance rating and A-weighted sound pressure level, we will obtain a linear relationship between annoyance rating and $\left(L_{A e q, T}\right.$, $\left.L_{C e q, T}\right)$.

\section{Discussion}

It is clear from Tables 3, 4 and 6 that the difference between $L_{C}-L_{A}$ for most of the measurement locations (control rooms, laboratories and offices) in the three electrical power stations exceeds $15 \mathrm{~dB}$. In 
Shopra Elkhiema electrical power plant $L_{C}-L_{A}$ ranges from 51.3 to 26.2. In case of Cairo West electrical power station $L_{C}-L_{A}$ ranges from 14.2 to 18.7 , thus not far from the value of $15 \mathrm{~dB}$. Also, in case of Cairo South electrical power station $L_{C}-L_{A}$ ranges from 14 to 18.1 , thus it was lower than the value 15 by 1 at office number 5 . It is clear that the difference between $\mathrm{C}$ - and A-weighted sound pressure levels $\left(L_{C}-L_{A}\right)$ is commonly used to identify the frequency composition of noise. This difference is an indicator for the presence of the amount of low frequency noise energy in the noise (PERsson, 1995). From Fig. 1, we can see that both control room and laboratory which are near turbine which is the source of low frequency noise in these two places. The values of sound pressure level at frequencies of $25,50,125,200$ and $250 \mathrm{~Hz}$ for control room and laboratory are higher than that for offices. Office No.1 is located near water pumps which are situated under the ground and are a source of noise and vibrations causing complaints from most of the workers.

The values of the equivalent-continuous A-weighted sound pressure level $L_{A e q, T}$ in Shopra Elkhiema electrical power station range from 48.9 up to $65.9 \mathrm{~dB}$ and the values of $L_{C e q, T}$ range from 66.1 to $81.5 \mathrm{~dB}$. The values of the equivalent-continuous A-weighted sound pressure level $L_{A e q, T}$ in Cairo West electrical power station range from 41.1 up to $56.3 \mathrm{~dB}$ and the values of $L_{C e q, T}$ from 57.5 to 73.1 . Thus, the control room has the highest values of $L_{A e q, T}$ and $L_{C e q, T}$ and the annoyance rating has the highest values at the control room.

From Fig. 2 we can see that the two control rooms have higher values of sound pressure level than offices and laboratories at the frequencies 31.5, 40, 50, 100, 160 and $200 \mathrm{~Hz}$. The two control rooms have the values of $L_{A e q, T}=55.1,55.4 \mathrm{~dB}$ and office number 3 has the lowest values of $41.1 \mathrm{~dB}$. Cairo West electrical power station is newer than Shupra Elkhiema electrical power station, so we can find that control room of Shopra Elkhiema has higher value of $L_{A e q}$ than that of control room of Cairo West electrical power station. The control room No.1 is located near turbine which emits low frequency noise and vibrations. Cairo West electrical power station has two laboratories: one of them is above water pumps which emit low frequency noise and vibration. This laboratory has some cracks and a hole in the ground which is above the water pump region and LFN can pass through this hole into the laboratory.

From Fig. 3 we found that control room and laboratory that are near turbine have the highest values of sound pressure level at frequencies of 50,63 , $80,125,160,200$ and $250 \mathrm{~Hz}$. The values of $L_{A e q, T}$ range from 57.6 to $70.5 \mathrm{~dB}$ and $L_{C e q, T}$ ranges from 71.6 to $86.9 \mathrm{~dB}$. The control room has the highest value for $L_{A e q, T}$ and $L_{A e q, T}$. The laboratory and of- fices are near water pumps but because Cairo South electrical power station is very old the load of worker were down from time to time and repairing will carried for it. From Figs. 1, 2 and 3 it is clear that the sound pressure level in $1 / 3$ octave band is $5 \mathrm{~dB}$ or more between some of neighbouring bands, the noise is said to be tonal in this case. There can be one or more tonal components in the spectrum of three stations. In this case the level in the frequency bands with tone is compared to hearing threshold level in the corresponding with Table 2 . It is found how much the increase of the tonal values is above the threshold level and makes difference with SPL in dB at $1 / 3$ octave band frequencies as shown in Table 7. A number of criteria has been developed for assessment of LFN (INUKAI et al., 1990; VERCAMMEN, 1992). In recent years, some European countries have adopted national criteria for low frequency noise including Sweden, Demark, Neither land, Germany and Poland, so we need further investigation to compare low frequencies curve in these power station with reference criteria curve.

The method uses the difference $L_{10}-L_{90}$ which has the advantage that it is generally available to environmental health practitioners. Tables 3, 4 and 5 show the difference of $L_{10}-L_{90}$ (noise climate) that implies that the relative threshold of acceptability were set at about the same level for the various beating tones, but that there was a clear difference around or less $5 \mathrm{~dB}$ for most of power stations, so we can simplify as follow:

$$
\begin{aligned}
& L_{10}-L_{90}<5 \text { no penalty } \\
& L_{10}-L_{90} \geq 5 \quad \text { penalty of } 5 \mathrm{~dB} .
\end{aligned}
$$

Like in Shopra Elkhiema power station in office No. 6 and No. 7 the differences are around 5.0 and 5.2.

It is worth noting that the A-weighting characteristics, commonly used to assess occupational exposure to noise, was established to predict loudness of sounds, but is not fully satisfied for the annoyance. It is clearly seen in Table 6 when we compare results for the control rooms for each station. We found that in the control room of Shopra Elkhiema, which has the highest value of $L_{A e q, T}$, the annoyance rating was not the highest. One of the control rooms in Cairo West station has the highest value of annoyance rating. Thus, no wonder that attempts have been made to replace A-weighting by alternative measures that predict better the effects of LFN. So far, the most popular solution is frequency analysis. For instance, current Polish, Swedish and German recommendations concerning the exposure to LFN in general environment are based on the frequency analysis in 1/3-octave bands (PIORR, WiETlake, 1990; PERSSON, 1997; MirowsKA, 2001). 


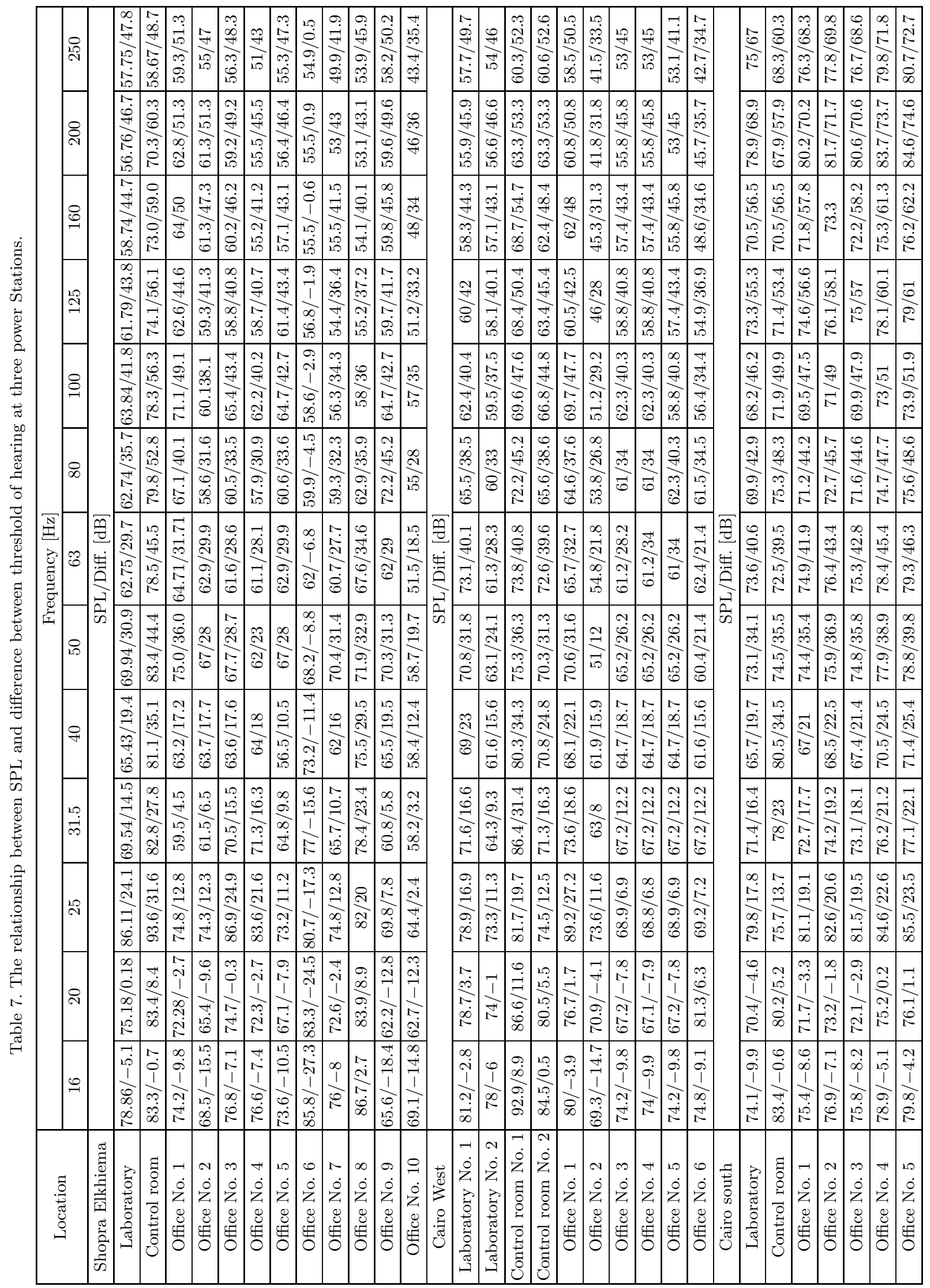




\section{Conclusion}

Regularity authorities must accept that annoyance by LFN presents a real problem which is not fully described by the commonly used assessment methods. Annoyance has roots in complex of responses which are moderated by personal and social characteristics of the complaints. The field study is more realistic than laboratory studies. The obtained results of the field measurements suggest that the method based on the equivalent continuous A-weighted SPL with Cweighted SPL seems to be able to predict quite well annoyance and negative effects from LFN in the occupational environment. $L_{C}-L_{A}$ was used as indicator for the presence of LFN in workplaces. Most of studied places (control rooms, laboratory and offices) in three electrical power stations have values of $L_{C}-L_{A}>15$ which indicate the presence of LFN. Two noise metrics (i.e. $L_{A e q, T}$ and $\left.L_{C e q, T}\right)$ seem to be reliable predictors of annoyance exclusively from LFN. The annoyance rating values range from 65.33 to 87.14 corresponding to "quite annoyed" on the 100-score scale. It is clear that workers at control rooms are more affected by LFN than others. There is an increasing acceptance that low frequency noise needs to be specifically attended to, but only a few countries have adopted specific guidelines for low frequency noise.

\section{References}

1. Berglund B., Hasten P., Job R.F. (1996), Sources and effects of low-frequency noise, J. Acoust. Soc. Am., 99, 5, 2985-300.

2. Berglund B., Lindvall T., Schwella D., Goh K-T. (2000), Guidelines for community noise, World Health Organization.

3. Broner N. (1978), The effects of low frequency noise on people, J. Sound. Vib., 58, 483-500.

4. Broner N., Leventhall G. (1983), Low frequency noise annoyance assessment by low frequency noise rating, J. Low Freq. Noise \& Vib., 2, 20-28.

5. DIN 45680 (1997), Measurement and Assessment of Low-frequency Noise Immissions in the Neighbourhood [in German], Deutches Institut für Normung, Berlin.
6. Inukai Y., Taua H., Utsugi A. (1990), A new evaluation method for low frequency noise, Proceeding of the Inter-Noise., 90, 1441.

7. ISO 226 Acoustics (2003), Normal equal-loudness contour.

8. ISO1996-1 Acoustics (2003), Description, measurement and assessment of environmental noise - Part 1: Basic quantities and assessment procedures.

9. Leventhall G., Pelmear P., Benton S. (2003), A review of published research on low frequency noise and its effects, Department for environment, food and rural affairs, crown copyright, www.derfra.gov.uk.

10. Mirowska M. (2001), Evaluation of low-frequency noise in dwellings. New Polish recommendations, J. Low Freq. Noise \& Vib., 20, 2, 67-74.

11. Oliva D., Hongisto V., Keränen J., Koskinen V. (2011), Measurement of low frequency noise in rooms, Finnish Institute of Occupational Health, Helsinki, $66 \mathrm{pp}$.

12. Pawlaczyk-€uszczyńska M., Szymczak W., DuDARewicz A., Śliwińska-Kowalska M. (2006), Proposed criteria for assessing low frequency noise annoyance in occupational settings, International Journal of Occupational Medicine and Environmental Health, 19, 3, 185-197.

13. Persson Waye K. (2002), Effects of low frequency noise in the occupational environment - present knowledge base, [in:] Proceeding of the inter-noise, Selamet A., Singh R., Maling G.C. [Eds.], Dearborn, MI, USA.

14. Persson Waye K. (1995), On the effects of environmental low frequency noise, Dissertation thesis, Gothenburg University, Gothenburg, Sweden.

15. Persson WAYE K. (1997), Estimation of environmental low frequency noise - a comparison of previous suggestions and the new Swedish recommendation, [in:] Proceedings of the 8th International Meeting on Low Frequency Noise and Vibration, Tempest W. [Ed.], June 3-5, Gothenburg, A Multi-Science Publication, pp. 135-141.

16. Piorr D., Wietlake K.H. (1990), Assessment of low frequency noise in the vicinity of industrial noise sources, J. Low Freq. Noise \& Vib., 9, 3, 116-119.

17. Vercammen M.L.S. (1992), Low frequency noise limit, J. Low Freq. Noise \&Vib., 11, 7-13. 